\title{
The Key Factors of the Industrial Revolution 4.0 in the Malaysian Smart Manufacturing Context
}

\author{
Mohd Syaiful Rizal Abd Hamid, Universiti Teknikal Malaysia Melaka, Malaysia \\ Nor Ratna Masrom, Universiti Teknikal Malaysia Melaka, Malaysia \\ Nur Athirah Binti Mazlan, Universiti Teknikal Malaysia Melaka, Malaysia
}

\begin{abstract}
IR 4.0 is a new phase for the current trend of automation and data exchange in the manufacturing industry that focuses on cloud computing, interconnectivity, the internet of things, machine learning, cyber physical learning, and creating smart factories. The purpose of this article was to unveil the key factors of the IR 4.0 in the Malaysian smart manufacturing context. Two key data collection methods were used: (1) primary data from the face-to-face interview and (2) secondary data from the previous study. Significantly, five key factors of IR 4.0 were considered for this study: autonomous production lines, smart manufacturing practices, data challenge, process flexibility, and security. As a result, IR 4.0 for quality management practices might get high impact for the best performance assessment, which is addressed in various ways. Few studies in this area have been conducted in the Malaysian manufacturing sector to recommend the best practices implemented from the managers' perspectives. For scholars, this enhances their understanding and highlights opportunities for further research.
\end{abstract}

\section{KEYWORDS}

Industrial Revolution 4.0, Key Factors and Case Study, Quality 4.0, Quality Management, Smart Manufacturing

\subsection{INTRODUCTION}

Malaysia is one of the countries that are forging into the Industrial Revolution 4.0. From water to electricity to nuclear, Industrial Revolution 4.0, also known as Smart Factory 4.0 is digital technology to the emergence of a virtual world. It will have an impact on our daily life, and quality management is no exception.

Industrial Revolution 4.0 is a development vogue of smart industries where all use of proper equipment and is influenced by technological elements that are creating. The emergence of Industrial Revolution 4.0 affects all aspects of the field, including quality management. Industrial Revolution 4.0 derives from the word "Industrial Revolution 4.0," a project in the German government's advanced technology strategy that prioritises factory computing. To maintain Germany’s leading industrial

DOI: 10.4018/IJABIM.20220701.oa6

This article published as an Open Access article distributed under the terms of the Creative Commons Attribution License (http://creativecommons.org/licenses/by/4.0/) which permits unrestricted use, distribution, and production in any medium, provided the author of the original work and original publication source are properly credited. 
position, Industrial Revolution 4.0 was innovated and supported by the German Government (Felderer, 2016).

Before entering the era of Industrial Revolution 4.0, it starts the beginning with Industry Revolution 1.0. The occurrence of the Industrial Revolution 1.0 in the late 18th century began with a steam engine. While the Industrial Revolution 2.0 took place at the beginning of the 19th century, beginning with implementing mass production through interchangeable parts production, which created cars, telephones, aeroplanes. The Industrial Revolution 3.0 occurred in the early 20th century, which began with the emergence of technology and digital.

While the Industrial Revolution 4.0 occurred at this time or this century began with the emergence of IoT (Internet of Things) which was focused on Artificial Intelligence" (Felderer, 2016).

Industrial Revolution 4.0 is defined as the technological development of embedded systems for smart cyber-physical systems that occurred in the industry. The German Government first proposed and implemented it on its 2020 High-Tech Plan. Often known as "Smart Factory," Industrial Revolution 4.0 aims to sustain productivity and achieve high consumer and brand satisfaction. The effect of Industrial Revolution 4.0 was not only to introduce a new so-called "Smart Factory," but also the introduction of the word "Smart Product," where goods are embedded with sensors and smart processors which give customer experience and provide input to the manufacturer on the product's success in the field (Salimova et al., 2018).

The concept of smart manufacturing and Industry Revolution 4.0 are related to recent technological progress in which the Internet and supporting technologies (e.g. embedded systems). It serves as the mainstay to integrate or create human-machine interfaces, materials, products, production lines, and processes within and outside company processes to form a new kind of intelligent, linked, and agile value chain.

With the emergence of the Industrial Revolution 4.0, quality management has advanced through the use of smart electronics linked together in internal or external data networks (IoT), which can be controlled automatically without human intervention. These have had a positive and negative impact on the approaches to quality management (Foidl and Felderer, 2016). In general, the objective of quality management was to benefit business stakeholders, where both organisations and business processes work together to produce value-for-money products and services that meet and exceed customer satisfaction positively.

In most recent studies carried out by authors such as Kusiak (2018); Diamandescu (2015); Rauch et. al (2019) in the areas of quality management and Industrial Revolution 4.0 seem to lack to see how the current quality management approach need to change, improvise and to be in line with the development of the Industrial Revolution 4.0 particularly in the area of smart manufacturing. However, there is a challenge on how to use extensive information for quality management, of which Industrial Revolution 4.0 proposes a solution. While this formative study is exploratory in nature, our findings provide a significant insight that contributes to unveiling the key factors of the research. For instance, contribution to knowledge provides insight into the main factors of Industrial Revolution 4.0: autonomous production line, smart manufacturing practices, data challenge, process flexibility, and security. Then, this research could contribute to practicality, which means it could be used in industry.

The objective of this study was to unveil the key factors of industrial revolution 4.0, particularly in the Malaysian smart manufacturing context. Therefore, the research question of this study is, "What are the key factors of Industrial Revolution 4.0 particularly for Malaysian smart manufacturer?"

In saying that, this article aims to answer the research questions, "What are the key factors of Industrial Revolution 4.0 particularly for Malaysian smart manufacturer?".

The rest of the paper is structured as follows: the first section provides the literature review of smart manufacturing in Industrial Revolution 4.0. The second section discusses the methodology of the study. In the third section, the paper continues with the findings and discussion. The final section discusses the conclusion of the study. 


\subsection{BACKGROUND}

\subsection{Smart Manufacturing in Industrial Revolution 4.0 for Quality Management}

Industrial Revolution 4.0 is a technological revolution in 2015 (Kagermann, 2015). It is powered by several innovative developments on the Internet that redefine how companies create, form, distribute, and service goods (Liao et al., 2017). Industrial Revolution 4.0 technology has led to growing skills, reducing downtimes, reducing costs, separating itself from the competition and improving service, delivery and performance (Liao et al., 2017; Jones and Pimdee, 2017). An Industrial Revolution 4.0 implementing company utilises ICTs to transform vertical and horizontal business processes in realtime digitally and includes full value creation and delivery systems (Sanders et al., 2016; Satoglu et al., 2018; Kamble et al., 2020).

Industrial Revolution 4.0 makes factories more intelligent, flexible, and dynamic by equipping manufacturing with sensors, actors, and autonomous systems (Roblek, Mesko \& Krapez, 2016). Accordingly, machines and equipment will achieve high levels of self-optimisation and automation. Besides, the manufacturing process can fulfil more complex and qualified standards and requirements of products, as expected (Roblek, Mesko \& Krapez, 2016). Thus, intelligent factories and smart manufacturing are the major goals of Industrial Revolution 4.0 (Sanders, Elangeswaran \& Wulfsberg, 2016).

Industrial Revolution 4.0 makes value-added integration occur horizontally and vertically in the manufacturing process (Shafiq et al., 2015; Stock \& Seliger, 2016). Specifically, the horizontal procedure is integrated with value creation modules from the material flow to the logistics of the product life cycle. In contrast, the vertical procedure integrates product, equipment, and human needs with different aggregation levels of the value creation and manufacturing systems. Intelligence and digitisation are integrated from the raw material acquisition to the manufacturing system, product use, and the end of product life. Lasi et al (2014) point out that Industrial Revolution 4.0 drives manufacturing in two directions: the application-pull procedure and the technology-push procedure. The former induces dynamic changes caused by a new generation of industrial infrastructure. The latter requires higher level mechanisation, digitalisation and networking, and miniaturisation.

In Industrial Revolution 4.0, the manufacturing procedure will require more sensors, actors, microchips, and autonomous systems due to the quick development of technologies (Lasi et al, 2014; Oses et al., 2016; Roblek, Meško \& Krapez, 2016; Rubmann et al., 2015; Sanders, Elangeswaran \& Wulfsberg, 2016). Advanced methodologies of analytics, cyber-physical system (CPS), and energy conservation measures (ECM) will be implemented in manufacturing, as well (Oses et al., 2016). Based on high-frequency energy metering, Oses et al. (2016) propose a model for an injection machine to estimate the adjusted baseline with lower risks and uncertainties in measuring and verifying energy conversation. Shafiq et al. (2016) propose the assimilation of virtual manufacturing at three levels: virtual engineering objects, virtual engineering processes, and virtual engineering factories. The integrated mechanism of the three levels will help build the structure of Industrial Revolution 4.0 and for achieving a higher level of intelligent machines, industrial automation, and advanced semantic analytics.

Smart manufacturing is a phenomenon that defines the development model of Industrial Revolution 4.0 (Kusiak, 2018). Recently, several researchers have conducted studies on smart manufacturing developments (Cui et al., 2020; Ghobakhloo, 2019). Kang et al. (2016) described essential smart manufacturing technologies. Helu et al. (2016) presented data-driven decision-making criteria in smart manufacturing. Zhong et al. (2017) highlighted how wireless technologies enabled interactions with smart manufacturing objects. Zhong et al. (2017) illustrated the interaction of wireless technology with smart manufacturing products. In their research, Kusiak (2018) highlighted the six pillars of smart factories. Kusiak (2018) has stated that the six pillars of smart manufacturing consist of materials, data, manufacturing technology and processes, resource-sharing and networking, predictive engineering, and sustainability. 
Sustainability is of utmost importance in manufacturing in the Industrial Revolution 4.0 model, and production can be essential to sustainability (Siemieniuch et al., 2015). Chun and Bidanda (2013) discussed sustainability in manufacturing and green supply chain management. Sjödin et al. (2018) highlighted the smart factory concept (Rauch et al., 2017; Latorre-Biel et al., 2018), increasing process performance, decreasing operating costs, and improving product quality and improve safety and sustainability. The principles of sustainability guide the creation of production processes. The sustainability requirements to be considered in sustainable manufacturing are examples of sustainable product design and sustainable materials production.

Zonnenshain and Kenett (2020) have stated that quality has developed in six steps involving the quality of the product, process quality, service quality, quality management, design quality, and quality of information. The latter is mainly related to the development of the Enterprise Resource Planning (ERP) framework and the software for the production execution system. In this way, businesses can now consider themselves a database-controlled discipline, from product to product and quality combined with Industrial Revolution 4.0 (Geissbauer et al., 2016; Kenett et al., 2020). Instead of presenting an accurate description of Quality 4.0, Zonnenshain and Kenett (2020) provided a model for quality management in which Quality 4.0 for companies that have implemented Industrial Revolution 4.0 embedded into their quality standard.

As such, Sisodia and Villegas Forero (2019, p. 35) further claim that Quality 4.0 refers to the digitalisation and effect of TQM on quality technologies, processes, and people. It builds on traditional tools in quality and also considers connectivity, knowledge, and automation to enhance performance and to make timely and detailed data-driven decisions that include all stakeholders and provide visibility and transparency. Consistent with this, Sony et al., (2020) reveal that quality 4.0 is the digitalisation of design quality, conformity quality, and output quality using digital technology.

Sisodia and Villegas Forero (2019) suggested a roadmap for a quality 4.0 switch, where the last step relates to data management. The authors have addressed the importance of building value within the organisation so that people can receive the right data and connect them at each hierarchical level with colleagues. Illés et al. (2017) illustrated how data can be obtained for consistency that has until now been unknown via I4.0 technology. The authors argue that the challenge is to find out where, how, and what to collect and to analyse the big data generated. Radziwill (2018) has written a paper on how is a typical Quality 4.0 setting data can generate value for employees and stakeholders in general if the organisation can handle unique features (Beard- Gunter et al. 2019). These are links, which help to identify what kind of data people need to receive and where, the knowledge that enables people to understand and react to received information, automation, or automated transmission of data when needed. Data can also be collected during the product cycle for enhancement of design quality, according to Sony et al. (2020); in this light, Big Data allows the understanding of the needs of consumers allowing businesses to achieve a better balance in design variables such as cost and value of the product.

Quality management is one of the fields that would greatly influence digitalisation. These five principles of Industrial Revolution 4.0 would have to be integrated into conventional quality control functions to produce high-quality goods and services. Quality 4.0 is also the digitalisation of design quality, conformity quality, and output quality using new technology. The implementation of digital technology can change the quality in different ways for example, by monitoring processes and extracting data from real-time sensors (Sony, 2018). Big data from these sensors can be further analysed to predict the organisation's quality problems and maintenance needs (Johnson, 2019). As such, quality 4.0 is much more than technology. It is a modern way to use digital technologies to boost the ability of companies to produce high-quality goods reliably.

Quality 4.0 would lead to changes in the supply chain. In a new study by the Boston Consulting Company, American Society for Quality and others, manufacturing and R\&D have shown themselves to be highly beneficial since quality 4.0 is applied (Küpper et al., 2019). In manufacturing, the perceived importance of value in the shop floor to achieve a conformity standard can change maritime 
by implementing intelligent diagnostic tools. The research and development effect of Quality 4.0 will influence design quality as data on the use of the product are passed to designers through end-to-end incorporation of industry 40 (Cheng et al., 2016). Users' needs can therefore be better mapped and manufacturers' products and services designed to justify a study that collects and analyses the key ingredients that are vital for successful quality 4.0 implementation.

\subsection{Synthesis of Smart Manufacturing in Industrial Revolution 4.0}

Having reviewed the pertinent of Industrial Revolution 4.0 literature and its characteristics allows the researchers to further understand how this Industrial Revolution 4.0 context may give the impact of respective quality management and also reflect on the key factors of this Industrial Revolution 4.0.

It is becoming clear that the features of Industrial Revolution 4.0 provided a promise for business excellence. The ability of the business to perform more efficiently by utilising the technology to the maximum. Other than that, production processes can work on themselves for optimal production by this "Smart Factory". There are possible challenges and problems posed to it while transitioning from the traditional model of the industry to Industrial Revolution 4.0. According to Thamsen (2016), the attributes of quality management are goals, rules, feedback and participation, customer satisfaction, and continual efficiency for waste reduction, top managerial competencies, and improved documentation like the ISO 9001 system. Additionally, Industrial Revolution 4.0 still has some security and safetyrelated ambiguities. Connectivity issues and lack of expertise needed can cause huge damages. It is very risky to effectively run high technology. Production failure can cause high losses and could be harmful to humans.

With the above background information on the overview of Industrial Revolution 4.0 and particularly in the smart manufacturing context, we can now turn to the key factors of the Industrial Revolution 4.0, particularly in the Malaysian smart manufacturing context, and looking from the big picture at the impact of Industrial Revolution 4.0 on quality management in the industry at large.

\subsection{RESEARCH METHODOLOGY}

A literature survey is used to establish research methodologies. It was discovered after a thorough review of previous research and case studies on key factors of the Industrial Revolution 4.0 in Malaysian smart manufacturing context. After thoroughly reviewing literature published in scholarly journals or through case studies, a few researchers (Sony et al., 2020; Sisodia and Villegas Forero 2019; Beard- Gunter et al. 2019) have researched quality management in Industrial Revolution 4.0 on smart manufacturing. However, there is still a gap in these studies when it comes to implementing quality management in smart manufacturing. Only a limited amount of empirical work on quality management in the smart manufacturing industry exists, and only a few case studies have been completed by a few researchers.

This paper is an exploratory qualitative study. A systematic approach to the literature review is based on the knowledge that gives a major role in evidence-based practices (Denyer \& Tranðeld, 2008; Rousseau, Manning, \& Denyer, 2008; Tranfield, Denyer, \& Smart, 2003) was adopted in this research. Process in getting a literature review that has been conducted include 'Industrial Revolution 4.0', and 'Smart Manufacturing'.

Essentially, systematic reviews are formulated around the research question. In this study, our key aim is to answer the question of "What are the key factors of the Industrial Revolution 4.0 particularly for Malaysian smart manufacturer?". Next, after analysing a patent of the literature, the researchers have adopted a case study approach to illustrate how this phenomenon - the characteristics are applied to the real-world context. This is supported by Yin $(2003,2012)$ who claims that for the evaluation research, the case can be used to document and analyses the implementation process.

A qualitative approach of thematic analysis was chosen as the tool of analysis for this study. Thematic analysis is the most popular qualitative method for analysing interviews in general. Thematic 
Table 1. Review Key Findings Relating to Industrial Revolution 4.0 and Smart Manufacturing

\begin{tabular}{|c|c|c|c|c|}
\hline No & $\begin{array}{l}\text { Reference } \\
\text { (Authors) }\end{array}$ & Findings & Types/Methods & Limitations/Implication \\
\hline 1 & Liao et al., (2017) & $\begin{array}{l}\text { Academic progress in subjects relevant } \\
\text { to the fourth industrial revolution in a } \\
\text { systematic manner in order to provide } \\
\text { insight into the topic's history, current, } \\
\text { and future. }\end{array}$ & $\begin{array}{l}\text { Qualitative and } \\
\text { Quantitative method }\end{array}$ & $\begin{array}{l}\text { Before conducting an investigation, } \\
\text { it is important to thoroughly } \\
\text { investigate the history and } \\
\text { circumstances of certain plans or } \\
\text { projects to prevent misinterpretation. }\end{array}$ \\
\hline 2 & Cui et al., (2020) & $\begin{array}{l}\text { Understanding of the performance } \\
\text { consequences of emerging technology, } \\
\text { as well as managerial insights into how } \\
\text { to foster economic and environmental } \\
\text { sustainability in the Industry } 4.0 \text { era }\end{array}$ & $\begin{array}{l}\text { Questionnaire survey } \\
\text { in China }\end{array}$ & $\begin{array}{l}\text { The Internet of Things, cloud } \\
\text { computing, big data, and analytics } \\
\text { are all examples of emerging } \\
\text { technology. In the age of Industry } \\
4.0 \text {, these innovative innovations } \\
\text { are integrated and interconnected, } \\
\text { and hence will have new growing } \\
\text { technologies in the future. }\end{array}$ \\
\hline 3 & Satoglu et al., (2018) & $\begin{array}{l}\text { Emphasises the relationship between Lean } \\
\text { Production and Industry } 4.0 \text { and suggests a } \\
\text { methodology for Industry } 4.0 \text { guidance in a } \\
\text { lean manufacturing setting. }\end{array}$ & $\begin{array}{l}\text { Basic concepts of lean } \\
\text { philosophy and lean } \\
\text { production systems }\end{array}$ & $\begin{array}{l}\text { Before implementing ICT, ensure } \\
\text { that there is a smooth flow of } \\
\text { information. }\end{array}$ \\
\hline 4 & $\begin{array}{l}\text { Sanders, } \\
\text { Elangeswaran \& } \\
\text { Wulfsberg } \\
\text { (2016) }\end{array}$ & $\begin{array}{l}\text { It reveals that committing to Industry } 4.0 \\
\text { makes a factory lean in contribution to } \\
\text { smart. }\end{array}$ & $\begin{array}{l}\text { Lean manufacturing } \\
\text { is first defined, and } \\
\text { different dimensions of } \\
\text { lean are presented. }\end{array}$ & $\begin{array}{l}\text { This paper bridges the gap between } \\
\text { these two worlds by identifying which } \\
\text { elements of Industry } 4.0 \text { relate to } \\
\text { which lean manufacturing dimensions. }\end{array}$ \\
\hline 5 & Kusiak, (2018) & $\begin{array}{l}\text { Manufacturing technology and processes, } \\
\text { materials, data, predictive engineering, } \\
\text { sustainability, and resource sharing and } \\
\text { networking are the six pillars that form } \\
\text { smart manufacturing. }\end{array}$ & Data Analytics & \\
\hline 6 & Helu et al. (2016) & $\begin{array}{l}\text { A shared understanding within the } \\
\text { manufacturing community that will allow } \\
\text { for the standardisation and innovation } \\
\text { needed to keep smart manufacturing } \\
\text { technologies in use. }\end{array}$ & & \\
\hline 7 & Sjödin et al. (2018) & $\begin{array}{l}\text { A preliminary maturity model for smart } \\
\text { factory implementation based on three } \\
\text { overarching principles: developing digital } \\
\text { people, implementing agile processes, and } \\
\text { configuring modular technologies }\end{array}$ & $\begin{array}{l}\text { data gathered from in- } \\
\text { depth studies }\end{array}$ & $\begin{array}{l}\text { To maximise output, develop digital } \\
\text { people, implement Agile processes, } \\
\text { and configure modular technologies }\end{array}$ \\
\hline 8 & Sony et al., (2020) & $\begin{array}{l}\text { The study revealed eight key ingredients } \\
\text { for the effective implementation of } \\
\text { Quality } 4.0 \text { in organisations, namely: } \\
\text { (i) handling big data (ii) improving } \\
\text { prescriptive analytics (iii) using Quality } \\
4.0 \text { for effective vertical, horizontal and } \\
\text { end-to-end integration (iv) using Quality } \\
4.0 \text { for strategic advantage (v) leadership } \\
\text { in Quality } 4.0 \text { (vi) training in Quality } 4.0 \\
\text { (vii) organisational culture for Quality } 4.0 \\
\text { and lastly (viii) top management support } \\
\text { for Quality } 4.0 \text {. }\end{array}$ & $\begin{array}{l}\text { A narrative literature } \\
\text { review }\end{array}$ & $\begin{array}{l}\text { When implementing Quality } 4.0 \text {, } \\
\text { each ingredient should be effectively } \\
\text { analysed, and measures taken so that } \\
\text { the implementation of Quality } 4.0 \\
\text { is effective. }\end{array}$ \\
\hline 9 & $\begin{array}{l}\text { Sisodia and Villegas } \\
\text { Forero (2019) }\end{array}$ & $\begin{array}{l}\text { A description of Quality } 4.0 \text { is provided, as } \\
\text { well as a general roadmap for transitioning } \\
\text { to Quality } 4.0 \text {, which includes six } \\
\text { sequential phases and is applicable to } \\
\text { a variety of organisations planning to } \\
\text { implement Quality } 4.0 \text {. }\end{array}$ & $\begin{array}{l}\text { a qualitative research } \\
\text { strategy with a case study } \\
\text { design and an abductive } \\
\text { approach }\end{array}$ & $\begin{array}{l}\text { The roadmap does not propose a } \\
\text { particular set of digital tools for } \\
\text { quality work since it is general. }\end{array}$ \\
\hline 10 & $\begin{array}{l}\text { Beard- Gunter et } \\
\text { al. } 2019\end{array}$ & $\begin{array}{l}\text { Good game design and TQM in socio- } \\
\text { technic frameworks have positive } \\
\text { consequences for improving interaction } \\
\text { and efficiency in companies adopting } \\
\text { Industry } 4.0 .\end{array}$ & $\begin{array}{l}\text { a systematic literature } \\
\text { review }\end{array}$ & $\begin{array}{l}\text { Increasing participation in HCI } \\
\text { systems, similar to what has } \\
\text { been seen in companies that have } \\
\text { successfully introduced TQM, could } \\
\text { lead to increased productivity in } \\
\text { companies operating in Industry } \\
\text { 4.0's highly technical environments. }\end{array}$ \\
\hline
\end{tabular}


analysis is a tool for 'identifying, analysing, and reporting trends (themes) within the data,' according to Braun and Clarke (2006). (2006, p.79). Since a "rigorous thematic approach can generate an informative analysis that addresses specific research questions," this study chose this process (Braun and Clarke, 2006, p.97). Furthermore, this approach complemented the research questions by allowing for an investigation of the interview data from two perspectives: first, from a data-driven perspective and one focused on inductive coding; and second, from a research question perspective to see whether the data is compatible with the research questions and provided enough detail.

Moving on from this, the researchers also want to focus and be specific at the highest level possible. As a result, researchers chose Toyo-Memory Technology and Intel Malaysia, as there are one of the companies that can fit well with the Industry 4.0 model. These two companies devote a significant amount of time and resources to fostering an Industrial Revolution 4.0 ecosystem for communities that promote the commitment and innovation in practices in their daily operation. Therefore, the key reason for selecting these two companies is based on the premise that they operate successfully in the Industrial Revolution 4.0 context (i.e. The Malaysian pioneer project for Industrial Revolution 4.0), fulfilling the criterion purpose and providing the exceptional case, as they are the stepping stones and benchmarking for the other companies to learn from them.

As a result, in conducting this research, two key data collection methods (qualitative methods) were used: (1) Primary data from face-to-face interviews with Toyo Memory Technology and Intel Malaysia (2) Secondary data from previous studies. Accordingly, this review of the previous study allows the researchers to understand better the pertaining issue regarding the key factors in implementing the practice of Industrial Revolution 4.0.

As such, in this study, respondents were selected based on their background of the manufacturer that participated and living in the environment of Industrial Revolution 4.0, particularly in the Smart Manufacturing context. Turner (2010) and Creswell (2007) indicated that a researcher should conduct sampling strategies to get qualified respondents that will provide appropriate and valuable information. Respondents were chosen based on certain categories and characteristics that meet the research outcomes. They have; (i) implemented quality management practices; (ii) various experiences in managing issues over quality management; (iii) moving towards digital manufacturing; (iv) and living in the environment of Industrial Revolution 4.0 context such as smart manufacturing, digital manufacturing, fully automation and others.

In short, the respondents consisted of experts who worked in positions ranging from Engineer up to General Manager of the Toyo-Memory Technology and Intel Malaysia. Besides, respondents were selected for this study according to the following criteria: they were currently working as a manager or engineer position. They were viewed as making significant contributions to their organisations and the field. To ensure the quality of the interview data, the respondents' experience had to include at least three years of working in the organisation. Participation was voluntary, with the managers and engineers offering selections and suggestions. The respondent's details are shown in Table 1 as follows.

Initially, the aim of conducting these interviews was to enrich the information regarding the companies' values and practices, as this allowed the researchers to understand better what people are thinking and saying. Thus, the researchers gained information on the key factors to manage quality performance in the organisation, and the researchers examined the association and prevalence of different quality approaches in the context of smart manufacturing.

\subsection{RESEARCH FINDINGS \& DISCUSSION}

\subsection{Northern Corridor Economic Region (NCER) Overview}

Northern Corridor Economic Region (NCER) was established in 2007 as one of the economic corridors to provide fair growth in the four states in the northern region of Peninsular Malaysia, the state of Kedah, Northern Perak, Perlis, and Pulau Pinang. This region has exhibited strong economic progress, with a higher annual gross domestic product (GDP). NCER's GDP increased by $10.3 \%$ to 
Table 2. Respondents Details

\begin{tabular}{|l|l|l|}
\hline \multicolumn{1}{|c|}{ Respondent } & \multicolumn{1}{|c|}{ Designation } & \multicolumn{1}{c|}{$\begin{array}{c}\text { Years of } \\
\text { Experience }\end{array}$} \\
\hline $\begin{array}{l}\text { General Manager 1, Toyo-Memory } \\
\text { Technology (TMT) }\end{array}$ & $\begin{array}{l}\text { General Manager } \\
\text { Chief Quality Assurance \& Chief Production Officer }\end{array}$ & 31 Years \\
\hline Senior Manager 2, TMT & Senior Manager, Quality Assurance & 21 Years \\
\hline Senior Manager 3, TMT & Senior Manager, Internal Quality & 21 Years \\
\hline Senior Engineer 1, TMT & Senior Engineer, Quality Assurance & 16 Years \\
\hline Senior Engineer 2, TMT & Senior Engineer, Quality Assurance & 13 Years \\
\hline Senior Engineer 3, TMT & Senior Engineer, Internal Quality & 9 Years \\
\hline Senior Engineer 4, TMT & Senior Engineer, Internal Quality & 9 Years \\
\hline Manager 1, INTEL & Manager, Strategic Integration Management (SIM), Intel & 14 Years \\
\hline Engineer 2, INTEL & Engineer SIM, Intel & 11 Years \\
\hline Engineer 3, INTEL & Engineer SIM, Intel & 11 Years \\
\hline
\end{tabular}

RM215 billion in 2018, while the region's average household income increased by $9.2 \%$ to RM5,953 in 2018. Investment in the area increased to RM96.7 billion in 2018, up from RM79.9 billion in 2016 , resulting in the creation of nearly 120,000 new jobs and nearly 30,000 entrepreneurs. The region's remarkable economic growth has been fueled by key strategic sectors such as manufacturing, agriculture, and bio-industries, as well as services such as tourism, Global Business Services (GBS), logistics, and connectivity, which have helped NCER establish itself as a competitive region and investment destination.

The manufacturing sector in NCER has grown steadily since its inception, as evidenced by the RM80 billion in investments made by local and multinational companies. These businesses have introduced proprietary, cutting-edge production processes and products to NCER, which has resulted in knowledge and technology transfer. The electrical and electronics (E\&E) industry remains a major focus in the area, and it has fueled the expansion of other industrial parks in NCER. As a result, a network of supporting industries and complementary manufacturing clusters has developed, with positive spillover effects into the area.

As a result of its location within the Indonesia-Malaysia-Thailand Growth Triangle, NCER's manufacturing industry is boosted even further (IMT-GT). Its well-established logistics infrastructure of road, rail, air, and sea operations, as well as efficient support services, help to facilitate trade within and beyond the IMT-GT. NCER is strategically located within the Indonesia-Malaysia-Thailand Growth Triangle (IMT-GT). The region has the potential to develop strong international relations with Sumatra, Indonesia, and Thailand. Given their many complementarities, geographically proximity, and close historical and cultural ties. These can help boost the region's economy, creating a natural bloc for economic cooperation that would enable NCER to process, distribute, and export goods beyond Malaysia borders.

NCER has a strong manufacturing ecosystem with 40 years of evolution. The region's strong GDP growth is driven by manufacturing, in electrical and electronics, with the industry having been established since the 1970s. Since 1971, Pulau Pinang's Free Industrial Zones (FIZs) has hosted many multinational companies (MNCs). Many local companies have also grown in lockstep with the MNCs. Approximately, RM47.7 billion of investment in manufacturing projects from 2009 to 2016 was approved.

Further, Kulim Hi-Tech Park (KHTP), Kedah, plays an important role in driving the growth of the manufacturing industry. Established in 1996, it strives to provide world-class infrastructure for 
hi-tech manufacturing and serves as a strategic gateway to Southeast Asia for business and commercial expansion for various industries, particularly to be the forefront of Industrial Revolution 4.0 key players in Malaysia. To date, the park has attracted more than RM 34 billion of investment along with MNCs that have brought to their patented, state-of-the-art manufacturing technologies and products. Intel Malaysia and Toyo-Memory Technology (TMT) are one of the companies operating in Kulim Hi-Tech Park. The overview of these two selected companies is illustrated as follows.

\subsection{Overview of Case Study 1: Toyo-Memory Technology}

Toyo-Memory Technology (TMT) Sdn. Bhd. was established by Toyo-Kohan Co., Ltd. to manufacture Nickel Plated (NiP) Aluminium Substrates for Hard Disk has started in 1934 to supply plated steel to the canning industry. And it began producing NiP (Nickel Plated) Substrates in 1985, a natural step forward for a company that already possess surface treatment, grinding, and polishing technology. Then TMT has improved and developed its process and become one of the biggest substrate manufacturers in the world. It equips the plant with one of the most advanced and highest achieved automated production lines in the world. The advanced technology, started, implemented, and transferred to Toyo-Memory Technology Sdn Bhd. TMT develops the process and product, and its target is to be a quality leader in the world. Toyo-Memory Technology Sdn Bhd is a certified ISO 9001:2008 (Quality Management System, March 2005) and ISO 14,001:2004 (Environmental Management System, Dec 2007) company.

\subsection{Overview of Case Study 2: Intel Malaysia}

Intel, Kulim started as a manufacturer of motherboards in 1995 and has grown from one building to five buildings. The company manufactures and assembles computer and communication components like the microprocessor, chipsets, motherboards, wireless and wired connectivity products, and integrated digital technology platforms. As such, Intel, Kulim is an important site for building mobile modules and also has a research and development unit that focuses on early development.

Original equipment manufacturers (OEMs), original design manufacturers (ODMs), industrial and telecommunication equipment manufacturers are the key buyers for the components manufactured produced by Intel. Concerning this, there is another customer who buys Intel products through distributors, resellers, retailers, and other OEM channels around the world. Intel has three major customers (Hewlett Packard Company, Dell Inc., and Lenovo Group Limited) and many smaller direct and indirect customers.

With the above background information on the selected case study, we can now turn to the key aim of the study in which to investigate and reveal the key factors faced in Industrial Revolution 4.0, particularly in the Smart Manufacturing context. Throughout this section, the researchers present the reasoning (i.e. the key factors) behind the implementation in the organisation for achieving quality performance. In so doing, the authors have adopted the Thematic Analysis method as the main method to analyse the data.

\subsubsection{Thematic Analysis Method}

The purpose of this analysis is to identify common themes that emerged from the study. From the interview conducted, it is revealing that there are five key factors regarding the factors faced in Industrial Revolution 4.0, particularly in the Smart Manufacturing context which merit further analysis, namely, autonomous production line, smart manufacturing practices, data challenge, process flexibility, and security, Therefore, this section focuses on an analysis of the case study, according to the five identified themes.

"What are the key factors of Industrial Revolution 4.0 particularly for Malaysian smart manufacturers?" 


\subsubsection{Autonomous Production Line}

The plant of Toyo-Memory Technology (TMT) Sdn Bhd and Intel is equipped with one of the most advanced and highest achieved fully automated production lines in the world. The advanced technology, initiated, implemented, and continuously transferred to Toyo-Memory Technology Sdn Bhd. The IoT or smart manufacturing is implemented in the Toyo Memory Technology Sdn Bhd (TMT) and Intel Malaysia. As it is mentioned by TMT and Intel, almost all the production process is connected via sensors which it is being intelligent enough to make some types of the decision on incoming data immediately. TMT shares about the past where they need to collect data according to schedule, converted it to the desired state, put it into a database, and process it on an hourly, overnight, or weekly basis. After the Smart Manufacturing has been introduced in TMT, all the data collection is done by analytics programming (software) which the data has monitored, captures if there have any exceptions, assesses the data, decides and shares the output within a specific of time consisting of seconds or fractions of a second.

Furthermore, Intel claims that Industrial Revolution 4.0, which is using smart manufacturing, is completely given a new insight into them. This has been explained by Intel that they are starting to practice eco-friendly systems since Industrial Revolution 4.0 has been applied which is less of the documentation in their company and more on the online server (cloud-based portal) including the weekly or monthly meetings within them. All the data and information about Intel keep via a cloudbased portal and at the same time, the usage of A4 paper has been limited in the office. This gives the flexibility to Intel to improve collaborations and share all the information or data wherever they are. This is in line with Constantiou \& Kallinikos (2015), who claim that the Internet of Things (IoT) is a network of things connected and refers to an ecosystem comprising of objects, connectivity, and applications/services.

\subsubsection{Smart Manufacturing Practices}

TMT highlights that since applying Industrial Revolution 4.0, they can easily be identified as enduring customer needs and manufacturing well-engineered solutions. They said that they could schedule exactly when a particular machine requires particular services where they can predict maintenance possible and also guarantees up-time for the product supply as requested by customers. The implementation of smart manufacturing makes them respond proactively to each request by customers because all the product processing is connected via sensors.

TMT able to alert with the information of the maintenance problem on a compressor and get advance warning when a certain part needs to replace. Moreover, Intel also noted that many previously unavoidable production processes now can be skipped since applied to the smart manufacturing concept. This is because the usage of analytic programming that consists of SolidCAM and SolidWorks brings a hundred percent of accurate measurement as described in the drawing work by the engineering manager. This software provides unbelievable savings which can cut the cost of re-manufacturing the damaged product and at the same time increasing efficiency in the operations as well as a result in profits.

Besides, Intel also mentions that using 3D printing is also one of the opportunities for Intel to be more complex designs, a more rapid market launch because fewer tools are required where savings can be made on development time and waste reduction resulting in a more efficient manufacturing process. This has created space for Intel to create value and it is now possible to deliver a custom service at the price of a mass product.

Industrial Revolution 4.0, particularly Smart Manufacturing also gives an opportunity to TMT and Intel to improvising the overall production process where the TMT and Intel are able to increase quality performance in their organisation. This is because the Internal Quality department, TMT mentioned that the product can be produced in a very short time with very high quality which can also reduce the cost of re-manufacturing in the event of any damage to the product. As a result of this, the usage of smart data is one of the solutions that can generate added value by processing, enhancing, or 


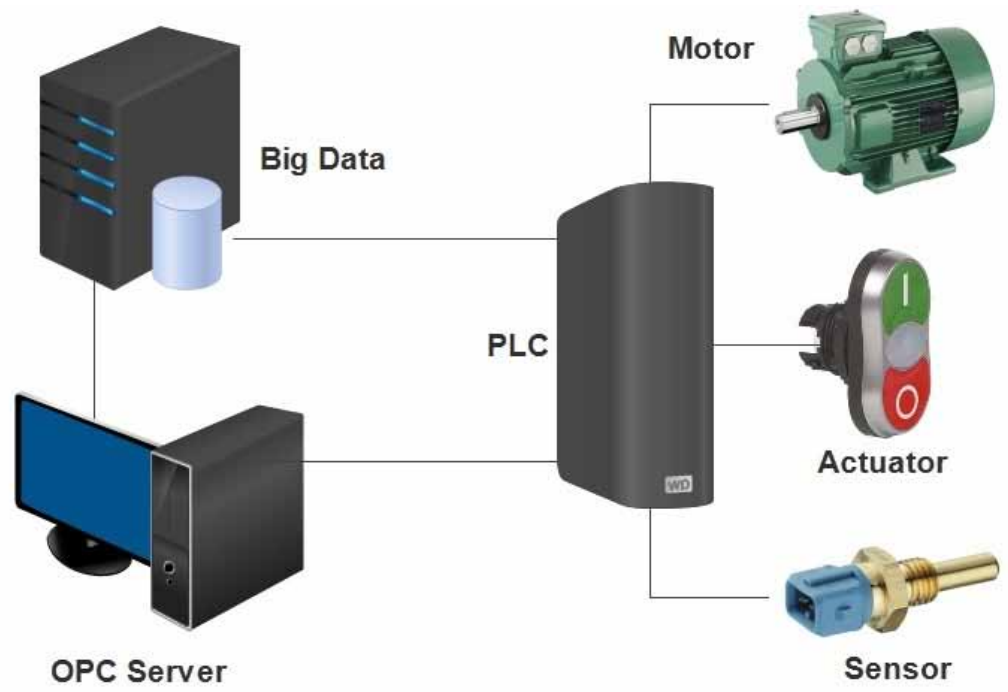

Sources: Khan and Turowski (2016)

converting existing data. Companies can also improvise quality performance by further developing existing solutions relating to smart manufacturing technologies.

\subsubsection{Data Challenge}

Users of smart manufacturing can derive economic advantages at various stages of data processing where such solutions can generate opportunities in terms of processing, enhancing, or converting existing data for use in analytical tools or smart manufacturing infrastructures. While, Georgakopoulos and Jayaraman (2016) mentioned that such data poses various challenges and demands on new methodologies for storing, processing, and management and new algorithms, models, products, and visualisation techniques required to use and gain the actual benefits from the data. Specifically, there is a problem in which a plethora of intermediate solution exists for data management within a company, and it ranges from storing and exchanging data in the form of printouts, emails, excel sheets, proprietary applications, and using heterogeneous database solutions between various departments or production halls.

Accordingly, TMT claims that data processing plays an important part in it is so difficult to collect or make the actual data access, access the quality of data, data analysis, and create durable ecosystems for data applications. Before raw data can be used in smart data applications, it needs to structure, digitised, enhanced, and processed where these pre-processing stages needed labour and cost-intensive. If data are to be used for targeted analyses or new services, they must be accurate in terms both of syntax and, particularly, of content.

Moreover, TMT is responsible for maintaining and enhancing the quality of all product as directed by the superior express that their work determines the quality of data becomes difficult when it comes to high data sources, new data, unorganised or semi-structured because of the current lack of standards that offer criteria and benchmarks for data quality assessment. He said that they often require specific technical skills because the data tend to be in heterogeneous formats, and laborious conversion processes are required before it can be used where to accessing. This is consistent with the work of Khan and Turowski (2016), who emphasis that data acquisition is a challenging task in 
Industrial Revolution 4.0 due to different technologies, machines, sensors, CPS, IoT devices, and communication networks. Data collection, data pre-processing, and data transmission among the CPS of the complex and heterogeneous data in industry automation need a deep understanding of the big data tools (Khan and Turowski, 2016).

The sensor is a device that changes physical condition or action into an electrical signal and passes to PLC for further actions. The actuator receives an electrical signal from a PLC and converts it into physical action. PLC is a programmable unit where the instructions for automation are stored and takes a decision based on the input data from the sensors while actuators work on the PLC instructions. Sensors, actuators, and PLCs are made by different vendors and it generates heterogeneous data which is a big challenge for industrial big data (Khan and Turowski, 2016). Besides, Khan and Turowski (2016) also said that for inter-processes communication, the data must be in the same format which needs a transformation and cleaning of data in different situations where data needs to convert to visual forms to remotely online control the robotic machines. Keeping all these data before and after transformation is a challenge for Industrial Revolution 4.0.

As such, TMT faced challenges in terms of data after involving in Industrial Revolution 4.0 where TMT needs to hire people that have higher education in the IT sector and adequate in the field of computer science or train them to avoid the problem. The people must have specific skills to evaluate and interpret data as well as to provide data-based decision making. Thus, providing smart data also facing challenges on the cost side because it is very difficult for many companies to assess how much it will cost such as to predict how the costs of data storage and processing will develop. Before data have been processed, their value and quality are rarely known. A systematic analysis and pre-processing of the data which in turn frequently necessitates a lot of investment in time and money is required to reveal what potential rests in the data and what additional data sources need to be tapped.

\subsubsection{Process Flexibility}

Industrial Revolution 4.0 holds the promise of increased flexibility in manufacturing, along with mass customisation, better quality, and increased productivity. But it allows companies to cope with the challenges of producing an increasingly individualised product with a short lead-time to market and higher quality. Processes and systems at the production level are developed and managed isolated over time in various departments; therefore there is a need to bring process standardisation and synchronisations between various company departments to provide flexibility in an effective manner.

As such, according to Intel Malaysia, Industrial Revolution 4.0 already requires automation solutions to be highly cognitive and highly autonomous as an accelerant that allows individualised solutions, flexibility, and cost-saving in their processes. Hence, it gives them a bit of challenge in preparing advanced robotics and sensor technology which have the potential to increase autonomy further still and to speed up individualisation and flexibilisation. Further, TMT claims that there is a need to be more flexible in any process in the future. Even though the drone is already used in their process when wants to deliver spare part and inventories from one area to another area at any times, they are still in planning to establish flying maintenance robots to be a more flexible process, faster and more efficient in the future. However, they also mentioned that this technology could cause concern because of the slow development curve in absolute terms at the beginning, where the influence of such technologies is often underestimated, and disruptive market changes are missed.

It should be noted that the challenges faced by TMT after involving in Industrial Revolution 4.0 are in terms of process flexibility. One of the technologies that lead the process to be more flexible is $3 \mathrm{D}$ printing. 3D printing allows all the process higher complexity, inventory reduction, and faster delivery time without any additional cost. But, there are difficult to choose suitable materials; even 3D printing is already existing for all materials such as metal, plastic, ceramic, living cell, etc. Not all materials fulfil the industry requirement regarding porosity and other characteristics. Thus, sometimes because of the non-suitable material, the process will be disrupted where required quality has already been achieved, but long-lasting material qualification is still cannot be completed. 
Figure 2. Illustrates an example of security risks in an organisational business process: Online ordering for customers.

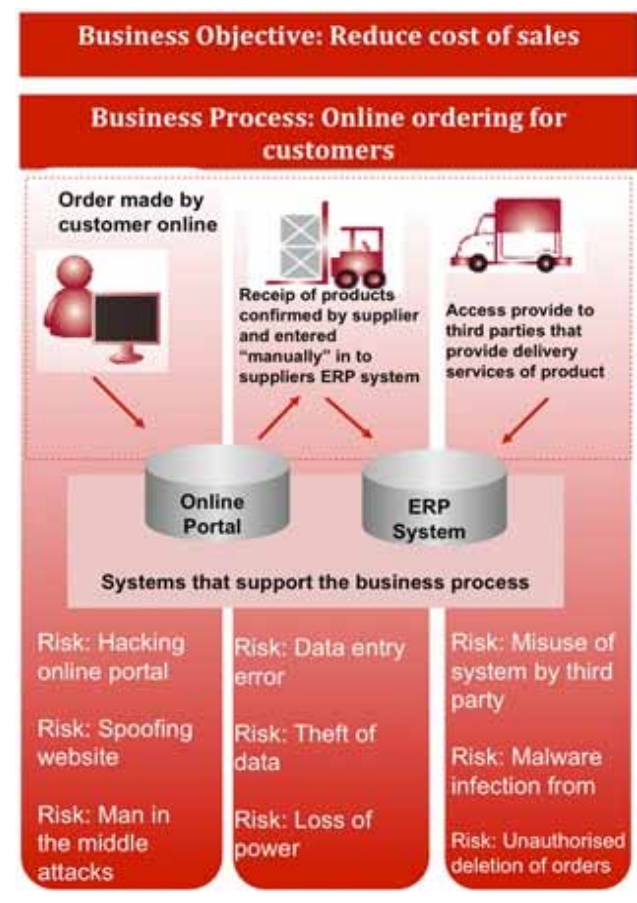

Sources: Pereire (2016)

\subsubsection{Security}

New technological solutions always carry security weaknesses, which most of the time reveals unexpected risks. In fact, with increasing reliance on technology to gain a competitive advantage, security issues have been one of the most critical and challenging requirements for conducting successful business. According to Khan and Turowski (2016), monitoring of such devices used in production is also a challenge from a software and hardware perspective, which is often ignored. As some IoT devices used at the production level have very limited processing capabilities which require new tools or methods and measurements to keep the devices secure instead of traditional methods. Serious measures are needed to restrict the threats posed by malfunctioning or hacked devices.

At Intel, asserting that Industrial Revolution 4.0 brings the Intel opportunity to be more advanced, but it is also very challenging to implement the process of software. Intel claims that the software process is a bigger challenge they have been faced after involving in Industrial Revolution 4.0 where the problems happen almost daily because of process disruptions due to misconfigurations, erroneous commands, software errors, or device failures. Software device has brought new enterprise technological changes, but with increased security risks.

Consistent with this TMT also mentioned that the most feared things are when happening software attack to what there have programmed in making a new product which with using 3D printer where it can be programmed directly to print the design created using both SolidWorks and Inverter. The design is created via drawing, design software, or the scanning of a physical object and then creating data. These data are then communicated to machines that execute the design, bringing it forth from the digital to the physical realm. Ideally, data from the process of creation and subsequent use is further captured, sparking ongoing cycles between the digital and physical realms. 
Therefore, the approach of defence which is known as "Security by Design" has been used in GMS to insert security measures into application programmers. It should strengthen single applications and embedded systems and enable them to self-protect against tampering, reverse-engineering, and malware insertion. On that note, according to Andrews (2017) founds that 73 percent of engineers surveyed believed investing in smart factories increased the risk of security breaches that are hackers accessing IT systems through an Internet of Things (IoT) asset. To prevent cyber-attack, the technology must provide clear features of security to the manufactures. Besides, it is also important for IT teams to work closely with the operational teams generally and provide support within a common IoT strategy (Andrews, 2017).

Physical attacks and cyber-attacks have evolved and are getting more sophisticated in order to compromise critical assets, and cause a serious and global impact. Therefore, it is encouraging fostering appropriate knowledge of security and awareness for good security practices to build secure systems from the beginning (Pereire, 2016).

\subsection{DISCUSSION AND CONCLUSIONS}

The key aim of this research is to answer, "What are the key factors of Industrial Revolution 4.0 particularly for Malaysian smart manufacturer?". In so doing, the researchers have reviewed the pertinent of Industrial Revolution 4.0 literature and its characteristics particularly in the smart manufacturing environment and this follows with the case study conducted.

Having carried out the thematic analysis and discussion regarding the key factors of Industrial Revolution 4.0 particularly for Malaysian smart manufacturer, we can confirm that the five key factors associated with these case study (i.e. TMT and Intel) that are autonomous production line, smart manufacturing practices, data challenge, process flexibility, and security.

The smart manufacturing practices has increased operating efficiency and productivity while also having a significant effect on the global economy. With smart manufacturing at the heart of this revolution, process flexibility enhances a company's ability to respond quickly to consumer demands and increase production system efficiency without incurring unnecessary costs or depleting capital. Moreover, specific technologies with analytical methods and tools are made to enable load-balancing control for a big volume of data effectively and efficiently into information and knowledge for smart manufacturing in Industrial Revolution 4.0. Lastly, encouraging fostering appropriate knowledge of security and awareness for good security practices, in order to build secure systems from the beginning.

Inevitable, TMT and Intel are facing challenges in terms of security because currently it has been seen the development of well-organised groups of the cybercriminal with excellent skills used to targeting specific industries, towards hacking sensitive information and intellectual property. According to Pereire et.al (2017), "Smart" is not just about creating more opportunities and building faster and more valuable communications; it is also about making responsible infrastructure for those gains and building robustness into the framework. Malicious hackers exploit software vulnerabilities in the system components to disrupt the whole production chain, potentially for long periods if attacks are physically destructive.

In terms of methodology, similar studies conducted in organisations similar to these respective companies are likely to yield similar results. The lessons are extracted, and therefore, this, on the one hand, may help quality assurance, and strategic policymakers to benchmark/evaluate where their organisations are now (See Morse, 1999; Stierand \& Dorfler, 2010). It also means that they do not need to start from scratch in predicting how quality management tools and techniques need to be corresponded or aligned to the Industrial Revolution 4.0 movement, as this study already provides some understanding and insights into this.

In terms of managerial implications, the paper asks if the main elements of the Fourth Industrial Revolution are especially relevant to Malaysian smart manufacturers. These key factors can aid managerial involvement in improving their skills and knowledge in enabling quality management 
in the context of smart manufacturing, which should be implemented in companies, as well as stakeholders. Not only must the organization consider which external stakeholders to communicate with and how to manage their interactions, but it must also consider how to assimilate, perceive, and learn from them in order to improve internal capability. To collect data and information, as well as to meet quality management needs, evaluation and better decision-making must be used in the company phase. Finally, the findings in terms of putting a focus on stakeholders, providing opportunities for smart manufacturing, and contributing to potential researchers' awareness.

This study has some limitations that should be noted, despite its merits as an exploratory review of the main factors of smart manufacturing. To begin, this study's scope is narrow, focusing solely on Industrial Revolution 4.0. Then, at the study site, only a few companies took part in Industrial Revolution 4.0. Therefore, we only used two cases from representative companies in this research, which are Toyo-Memory Technology (TMT) and Intel. As a result, future research could contribute more to new companies that participate in Industrial Revolution 4.0 and to find new key factors and examine the case on quality management in a smart manufacturing context.

\section{ACKNOWLEDGMENT}

The authors wish to thank Saifuddin Isa (the former Master student) and all the respective respondents during the interviews and for providing data throughout this study conducted. In addition, the authors acknowledge the support given by Universiti Teknikal Malaysia Melaka (UTeM), Centre of Technology Development (CTeD) for the financial support and facilities provided in completing this research. We will welcome any collaboration for this kind of research with an open arm. 


\section{REFERENCES}

Beard-Gunter, A., Ellis, D. G., \& Found, P. A. (2019). TQM, games design and the implications of integration in Industrial Revolution 4.0 systems. International Journal of Quality and Service Sciences, 11(2), $235-247$. doi:10.1108/IJQSS-09-2018-0084

Braun, V., \& Clarke, V. (2006). Using thematic analysis in psychology. Qualitative Research in Psychology, 3(2), 77-101. doi:10.1191/1478088706qp063oa

Cheng, G.-J., Liu, L.-T., Qiang, X.-J., \& Liu, Y. (2016). Industrial Revolution 4.0 development and application of intelligent manufacturing. Information System and Artificial Intelligence (ISAI), 2016 International Conference on, IEEE, 407-410.

Chun, Y., \& Bidanda, B. (2013). Sustainable manufacturing and the role of the international journal of production research. International Journal of Production Research, 51(23-24), 7448-7455. doi:10.1080/00207543.2012 .762135

Constantiou, I. D., \& Kallinikos, J. (2015). New games, new rules: Big data and the changing context of strategy. Journal of Information Technology, 30(1), 44-57. doi:10.1057/jit.2014.17

Creswell, J. W. (2007). Qualitative inquiry and research design: Choosing among five approaches (2nd ed.). Sage Publications, Inc.

Cui, Y., Kara, S., \& Chan, K. C. (2020). Manufacturing big data ecosystem: A systematic literature review. Robotics and Computer-integrated Manufacturing, 62, 101861. doi:10.1016/j.rcim.2019.101861

Denyer, D., \& Tranfield, D. (2008). Producing a systematic review. In D. e. Buchanan (Ed.), The Sage Handbook of Organizational Research Methods (pp. 671-689). Sage.

Diamandescu, A. (2016). The Significance of Total Quality Management Principles in Industrial Organizations. Global Economic Observer, 4(2), 92-99.

Felderer, M., Piazolo, F., Ortner, W., Brehm, L., \& Hof, H. J. (2016). Innovations in enterprise information systems management and engineering. 4th international conference, ERP Future 2015 - research, 1-17.

Foidl, H., \& Felderer, M. (2016). Research Challenges of Industrial Revolution 4.0. Quality Management Research. Challenges of Industrial Revolution 4.0 for Quality Management, 1-17.

Geissbauer, R., Vedsø, J., \& Schrauf, S. (2016). A Strategist's Guide to Industrial Revolution 4.0. Available at: https://www.strategy-business.com/article/A-Strategists-Guide-to-Industry-4.0

Georgakopoulos, D., \& Jayaraman, P. P. (2016). Internet of things: From internet scale sensing to smart services. Computing, 98(10), 1041-1058. doi:10.1007/s00607-016-0510-0

Ghobakhloo, M. (2019). Industrial Revolution 4.0, digitisation, and opportunities for sustainability. Journal of Cleaner Production, 252, 119869. doi:10.1016/j.jclepro.2019.119869

Helu, M., Libes, D., Lubell, J., Lyons, K., \& Morris, K. C. (2016). Enabling smart manufacturing technologies for decision-making support. In ASME 2016 International Design Engineering Technical Conferences and Computers and Information in Engineering Conference. American Society of Mechanical Engineers.

Illés, B., Tamás, P., Dobos, P., \& Skapinyecz, R. (2017). New challenges for quality assurance of manufacturing processes in Industrial Revolution 4.0. Diffusion and Defect Data, Solid State Data. Part B, Solid State Phenomena, 261(1), 481-486. doi:10.4028/www.scientific.net/SSP.261.481

Johnson, S. (2019). Quality 4.0: a trend within a trend. Quality, 58(2), 21-23.

Jones, C., \& Pimdee, P. (2017). Innovative ideas: Thailand 4.0 and the fourth industrial revolution. Asian International Journal of Social Sciences, 17(1), 4-35.

Kagermann, H. (2015). Change through digitization-value creation in the age of Industrial Revolution 4.0. In H. Albach, H. Meffert, A. Pinkwart, \& R. Reichwald (Eds.), Management of Permanent Change (pp. 23-45). Springer Gabler. 
Kamble, S., Gunasekaran, A., \& Dhone, N. C. (2020). Industrial Revolution 4.0 and lean manufacturing practices for sustainable organisational performance in Indian manufacturing companies. International Journal of Production Research, 58(5), 1319-1337. doi:10.1080/00207543.2019.1630772

Kang, H. S., Lee, J. Y., Choi, S., Kim, H., Park, J. H., Son, J. Y., Kim, B. H., \& Do Noh, S. (2016). Smart manufacturing: Past research, present findings, and future directions. International Journal of Precision Engineering and Manufacturing Green Technology, 3(1), 111-128. doi:10.1007/s40684-016-0015-5

Kenett, R. S., Swarz, R., \& Zonnenshain, A. (2020). Systems Engineering in the Fourth Industrial Revolution. In Big Data, Novel Technologies, and Modern Systems Engineering. John Wiley and Sons.

Khan, A., \& Turowski, K. (2016). A Perspective on Industrial Revolution 4.0: From Challenges to Opportunities in Production Systems. IoTBD.

Küpper, D., Knizek, C., Ryeson, D., \& Noecker, J. (2019). Quality 4.0 takes more than technology. Available at: https://www.bcg.com/publications/2019/quality-4.0-takes-more-than-technology.aspx

Kusiak, A. (2018). Smart manufacturing. International Journal of Production Research, 56(1-2), 508-517. do i: $10.1080 / 00207543.2017 .1351644$

Lasi, H., Fettke, P., Kemper, H. G., Feld, T., \& Hoffmann, M. (2014). Industrial Revolution 4.0. Business \& Information Systems Engineering, 6(4), 239-242. doi:10.1007/s12599-014-0334-4

Latorre-Biel, J., Faulín, J., Juan, A. A., \& Jiménez-Macías, E. (2018). Petri net model of a smart factory in the frame of Industrial Revolution 4.0. IFAC-PapersOnLine, 51(2), 266-271. doi:10.1016/j.ifacol.2018.03.046

Liao, Y., Deschamps, F., Loures, E. D. F. R., \& Ramos, L. F. P. (2017). Past, present, and future of Industrial Revolution 4.0-a a systematic literature review and research agenda proposal. International Journal of Production Research, 55(12), 3609-3629. doi:10.1080/00207543.2017.1308576

Morse, J. M. (1999). Editorial: Qualitative Generalizability. Qualitative Health Research, 9(1), 5-6. doi:10.1177/104973299129121622

Oses, N., Legarretaetxebarria, A., Quartulli, M., García, I., \& Serrano, M. (2016). Uncertainty reduction in measuring and verification of energy savings by statistical learning in manufacturing environments. International Journal on Interactive Design and Manufacturing, 10(3), 291-299. doi:10.1007/s12008-016-0302-y

Pfeiffer, S. (2016). Robots, Industrial Revolution 4.0 and humans, or why assembly work is more than routine work. Societies (Basel, Switzerland), 6(2), 16. doi:10.3390/soc6020016

Radziwill, N. (2018). Feature Quality 4.0 - let's Get Digital: The many ways the fourth industrial revolution is reshaping the way we think about quality. Quality Progress, 51(10), 24-29.

Rauch, E., Dallasega, P., \& Matt, D. T. (2017). Distributed manufacturing network models of smart and agile mini-factories. International Journal of Agile Systems and Management, 10(3-4), 185-205. doi:10.1504/ IJASM.2017.088534

Roblek, V., Meško, M., \& Krapež, A. (2016). A complex view of Industrial Revolution 4.0. SAGE Open, 6(2). Advance online publication. doi:10.1177/2158244016653987

Rousseau, D. M., Manning, J., \& Denyer, D. (2008). Evidence in management and organisational science: Assembling the field's full weight of scientific knowledge through syntheses. The Academy of Management Annals, 2(1), 475-515. doi:10.5465/19416520802211651

Rubmann, M., Lorenz, M., Gerbert, P., Waldner, M., Justus, J., Engel, P., \& Harnisch, M. (2015). Industrial Revolution 4.0. Boston Consulting Group.

Salimova, T.A., \& Vatolkina, N. (2018). Quality Management under the transition to the Industrial Revolution 4.0. RIA Standards and Quality, 972(6).

Sanders, A., Elangeswaran, C., \& Wulfsberg, J. (2016). Industrial Revolution 4.0 implies lean manufacturing: Research activities in Industrial Revolution 4.0 function as enablers for lean manufacturing. Journal of Industrial Engineering and Management, 9(3), 811-833. doi:10.3926/jiem.1940 
Sanders, A., Elangeswaran, C., \& Wulfsberg, J. P. (2016). Industrial Revolution 4.0 implies lean manufacturing: Research activities in Industrial Revolution 4.0 function as enablers for lean manufacturing. Journal of Industrial Engineering and Management, 9(3), 811-833. doi:10.3926/jiem.1940

Satoglu, S., Ustundag, A., Cevikcan, E., \& Durmusoglu, M. B. (2018). Lean production systems for Industrial Revolution 4.0. In Industrial Revolution 4.0: Managing the Digital Transformation. Springer Series in Advanced Manufacturing (pp. 43-59). Springer.

Shafiq, S. I., Sanin, C., Toro, C., \& Szczerbicki, E. (2015). Virtual engineering object (VEO): Toward experiencebased design and manufacturing for Industrial Revolution 4.0. Cybernetics and Systems, 46(1-2), 35-50. doi:1 $0.1080 / 01969722.2015 .1007734$

Siemieniuch, C. E., Sinclair, M. A., \& Henshaw, M. J. C. (2015). Global drivers, sustainable manufacturing and systems ergonomics. Applied Ergonomics, 51, 104-119. doi:10.1016/j.apergo.2015.04.018 PMID:26154210

Sisodia, R., \& Villegas Forero, D. (2019). Quality 4.0-How to Handle Quality in the Industrial Revolution 4.0 Revolution. Report No. E2019:128. Department of Technology Management and Economics Chalmers University of Technology, Göteborg, Sweden. https://odr.chalmers.se/bitstream/20.500.12380/300650/1/E2019_128.pdf

Sjödin, D. R., Parida, V., Leksell, M., \& Petrovic, A. (2018). Smart Factory Implementation and Process Innovation: A Preliminary Maturity Model for Leveraging Digitalisation in Manufacturing Moving to smart factories presents specific challenges that can be addressed through a structured approach focused on people, processes, and technologies. Research Technology Management, 61(5), 22-31. doi:10.1080/08956308.2018.1 471277

Sony, M. (2018). Industrial Revolution 4.0 and lean management: A proposed integration model and research propositions. Production \& Manufacturing Research, 6(1), 416-432. doi:10.1080/21693277.2018.1540949

Sony, M., Antony, J., \& Douglas, J. (2020). Essential ingredients for the implementation of Quality 4.0: A narrative review of literature and future directions for research. The TQM Journal, 32(4), 779-793. Advance online publication. doi:10.1108/TQM-12-2019-0275

Stierand, M., \& Dorfler, V. (2010). Iterative Learning from Investigating Extraordinary Chefs: Generalizability in Idiographic Research. International Journal of Contemporary Hospitability Management.

Stock, T., \& Seliger, G. (2016). Opportunities of sustainable manufacturing in Industrial Revolution 4.0. Procedia CIRP, 40, 536-541. doi:10.1016/j.procir.2016.01.129

Thamsen, P. U., \& Wulff, S. (2016). Industrial Revolution 4.0 and current Trends in the Pump industry A Look back on the ACHEMA 2015. Chemieingenieurtechnik(Weinheim), 88(12), 15-19. doi:10.1002/cite.201690002

Tranfield, D., Denyer, D., \& Smart, P. (2003). Towards a Methodology for Developing Evidence-Informed Management Knowledge by Means of Systematic Review. British Journal of Management, 14(3), $207-222$. doi:10.1111/1467-8551.00375

Turner, D. W. (2010). Qualitative Interview Design: A Practical Guide for Novice Investigators. Qualitative Report, 15, 754-760.

Yin, R. K. (2003). Case study research: Design and Methods (3rd ed.). Sage Publications.

Zhong, R. Y., Xu, C., Chen, C., \& Huang, G. Q. (2017). Big data analytics for physical internet-based intelligent manufacturing shop floors. International Journal of Production Research, 55(9), 2610-2621. doi:10.1080/00 207543.2015.1086037

Zonnenshain, A., \& Kenett, R. S. (2020). Quality 4.0 - The challenging future of quality engineering. Quality Engineering, 32(4), 614-626. Advance online publication. doi:10.1080/08982112.2019.1706744 
Mohd Syaiful Rizal Hamid was a former Dean of the Faculty of Technology Management and Technopreneurship at the Universiti Teknikal Malaysia Melaka, Malaysia. He received his Ph.D. in School of Engineering, Design Manufacture Engineering Management from the University of Strathclyde, United Kingdom. His fields of expertise are technology management and quality management. He has over fifteen years of teaching experience in the Department of Technology Management and involves actively for a few national scale research projects as well as working on many publications within his field of expertise such as Quality Tools and Techniques, Environmental Management, Service Management \& Sustainable Development. On top of it, he is also the panel auditor/assessor for academic accreditation body/quality assurance of higher education - i.e. Malaysian Qualifications Agency (MQA) for the areas of Quality \& Technology Management.

Nor Ratna Binti Masrom currently works as an academician in Universiti Teknikal Malaysia Melaka (UTeM). She has been working as an academician and researcher for more than 20 years and now she pursues her PhD in her interest area. Her research interests are quality management, supply chain management and information system.

Nur Athirah Binti Mazlan, actively as master researcher, currently pursues her Master of Science in Technology Management in Universiti Teknikal Malaysia Melaka(UTeM). She just graduated her Bachelor Degree in Technology Management (Technology Innovation) with Honors from the same institution. Her research interest is in Quality Management. 